CLINICAL STUDY

\title{
Increased circulating adiponectin levels and decreased leptin/soluble leptin receptor ratio throughout puberty in female ballet dancers: association with body composition and the delay in puberty
}

\author{
M A Donoso ${ }^{1,2,3}$, M T Muñoz-Calvo ${ }^{1,2,3}$, V Barrios ${ }^{1,2,3}$, G Garrido $^{4}$, F Hawkins ${ }^{5}$ and J Argente A $^{1,2,3}$ \\ ${ }^{1}$ Department of Endocrinology, Hospital Infantil Universitario Niño Jesús, Avenida Menéndez Pelayo, 65, E-28009 Madrid, Spain, ${ }^{2}$ Department of \\ Pediatrics, Universidad Autónoma, Madrid, Spain, ${ }^{3}$ CIBER Fisiopatología Obesidad y Nutrición (CIBEROBN), Instituto de Salud Carlos III, Madrid, Spain, \\ ${ }^{4}$ Instituto Nacional de Educación Física, Rendimiento Humano, Madrid, Spain and ${ }^{5}$ Department of Endocrinology, Hospital Universitario 12 de Octubre. \\ Universidad Complutense. Madrid, Spain
}

(Correspondence should be addressed to J Argente at Department of Endocrinology, Hospital Infantil Universitario Niño Jesús; Email: argentefen@terra.es)

\begin{abstract}
Introduction: Ballet dancers (BDs) have a negative energy balance related to physical training that results in alterations in body composition, sexual development, and adipokine secretion. Our aims were to study anthropometric parameters, body composition, and their relationship with adipokines throughout pubertal development.

Subjects and methods: We carried out a prospective follow-up study of 22 female Caucasian BDs (Tanner II stage) followed throughout puberty. Nutritional status was determined by measurement of height, weight, and body mass index (BMI). We calculated growth velocity, bone maturity, and body composition at Tanner stages II, III, and V by dual energy X-ray absorptiometry. Circulating leptin, adiponectin, and soluble leptin receptor (sObR) levels were determined.

Results: BDs presented a delay in skeletal maturation during puberty, without affectation of final height. Energy intake was deficient according to their physical exercise, and they had a delay of 1 year in the mean age of menarche. Leptin levels were decreased, whereas sObR and adiponectin levels were increased throughout puberty. The percentage of trunk fat, total fat mass, and fat of the extremities was decreased throughout the study period $(P<0.01)$. Lean mass was increased in the lower extremities, and bone mineral density was normal.

Conclusion: A negative energy balance together with maintained physical exercise induced modifications in body composition in BDs. Changes in leptin and adiponectin levels appear to be more related to total fat content than to BMI. Furthermore, the onset and delayed progress of puberty may be related with an inadequate energy balance due to increased exercise.
\end{abstract}

European Journal of Endocrinology 162 905-911

\section{Introduction}

In high-performance female ballet dancers (BD), the intensity of exercise, low energy consumption, type and amount of training, early age at initiation, low percentage body fat favored for the aesthetic appeal and required for complex movements (1), as well as pathological feeding habits and psychological stress, have been suggested as potential factors accountable for the delayed puberty, menstrual irregularities, and reduced growth potential. Growth during puberty depends on nutritional status, hormonal regulation, and genetic and environmental factors (2). Among environmental factors that can alter growth and sexual maturation are low body fat, stress, and intensive physical training (3). Their influence has been documented in different sports, but there is limited information on BDs, who have specific training and performance requirements. As optimal nutritional intake relative to physical training regimes is essential for normal pubertal development, this could be a problem in adolescents with strenuous training programs, while trying to maintain a lean figure (4). Indeed, energy expenditure may modify the effects of these factors on growth rate, body composition, and the relative proportions of lean and fat body mass (5).

Bone mineral density (BMD) is modified by exercise, nutrition, and dietary calcium intake (6). Cross-sectional studies have shown that high-impact weight-bearing activity is beneficial for the load-bearing sites of the skeleton (7). An increase in bone mass due 
to augmentation of bone size, density of skeletal areas and bone turnover has been demonstrated in adolescents performing intensive exercise. Indeed, strategies that enhance the acquisition of bone mass may be protective against osteoporosis (8).

Adipose tissue secretes adipokines that participate in energy balance, modulating insulin sensitivity, and lipid metabolism. Leptin appears to be important for pubertal onset and progression (9). Peripheral leptin levels are influenced by body fat mass and distribution, changing as puberty progresses (10). This peptide acts as a satiety signal that stimulates energy expenditure regulating body weight (11), with these actions being modulated by a soluble receptor (12). Physical exercise increases adiponectin levels (13) and the expression of its receptors in muscle (14), and this adipokine may have beneficial effects on the cardiovascular system $(15,16)$.

In BDs, serum leptin levels may influence the onset of puberty, and adiponectin levels may be related to the amount of exercise and lean mass (17). Thus, the aims of this study were as follows: i) to study weight, height, body mass index (BMI), growth velocity (GV), bone maturity, and the progression of puberty in BDs; ii) to analyze the levels of adiponectin, leptin, and its soluble receptor in BDs throughout pubertal development; and iii) to determine body composition and its relationship with the above parameters. We hypothesized that BDs have delayed pubertal development due to their increased level of exercise and energy expenditure that results in modifications in body composition and changes in circulating leptin levels.

\section{Subjects and methods}

\section{Subjects}

We carried out a prospective follow-up study of 22 female Caucasian adolescent BDs of the 'Conservatorio Nacional de Danza' in Madrid, Spain, with a mean age of $11.3 \pm 0.8$ years, and 30 healthy girls at different stages of puberty (with a mean age of $10.5 \pm 1.4$, $11.9 \pm 1.6$, and $15.1 \pm 1$ years at Tanner stages II, III, and $V$ respectively). BDs were enrolled in the study at Tanner stage II and followed during pubertal development, and the control group, consisting of females at different stages of puberty (II, III, and V), was recruited from a local school. Control girls (normal height and weight for age) were matched by age and weight to the BDs. BDs performed more than $18 \mathrm{~h}$ of exercise per week, and the control group performed $<3 \mathrm{~h} /$ week. No participant had any illness requiring medical treatment that could potentially affect bone metabolism. The study protocol was approved by the institution's ethics committee, and informed written consent was obtained from the girls and their parents.

\section{Methods}

Nutritional and auxological evaluation After the baseline study, BDs were evaluated every 6 months during 36 months in the different Tanner stages. Medical and physical examinations were performed at every visit. Nutritional status was determined by anthropometric measurements: height, measured by using a stadiometer (Holtain Ltd, Crymych, UK), weight on a SECA scale, and BMI, calculated as body weight (kg) divided by the squared standing height $\left(\mathrm{m}^{2}\right)$. All anthropometric measurements are expressed as SDS for age and sex referred to a normal Spanish population (18). Growth velocity (GV) was determined in $\mathrm{cm} /$ year and expressed in SDS for the chronological age. The target height in SDS was determined according to the following formula: target height $=$ mother's height + father's height $-13 / 2$, and the difference between the target height and the height (SDS) of each BD at each moment of the follow-up was calculated. Bone age (BA) was assessed annually with an X-ray of the left hand and wrist and determined according to the method of Greulich \& Pyle (19). Food intake was evaluated by using a 5-day (including Sunday) recall survey. Nutrient composition data were analyzed with the software package Nutritionist IV (San Bruno, CA, USA) (20).

Biochemical measurements Blood samples were collected after overnight fasting at $0800 \mathrm{~h}$ every 6 months during the study. Serum leptin and leptin soluble receptor levels were measured according to the manufacturer's directions by RIA and ELISA respectively (Millipore, St Charles, MO, USA and BioVendor Laboratory Medicine, Brno, Czech Republic) and as previously reported (10). Adiponectin levels were analyzed as previously reported (15) by RIA (Millipore). Intra- and interassay coefficient of variation (CV) were below $10 \%$ for all assays.

Bone density, body fat, and lean mass These parameters were evaluated at baseline (Tanner II) and Tanner III and V by whole-body and by dual energy X-ray absorptiometry (QRD-4500 W, Hologic, Waltham, MA, USA) using a standard procedure. The anatomical regions that were explored included the trunk, arms, legs, and total body. The in vivo $\mathrm{CV}$ using this technique was below $3 \%$ at each specific regional site. This corresponded to a s.D. of $\sim 415 \mathrm{~g}$ for fat mass and $933 \mathrm{~g}$ for fat-free mass $(21) . \operatorname{BMD}\left(\mathrm{g} / \mathrm{cm}^{2}\right)$, quantified as projected vertebral area of lumbar spine vertebrae $(\mathrm{LSv})$ from L1 to L4, femoral neck $(\mathrm{FN})$, femoral trochanter region, intertrochanter region, and Ward's triangle (WT) were measured at the different stages of puberty. Volumetric BMD of the lumbar spine (LSvBMD, $\mathrm{g} / \mathrm{cm}^{3}$ ) was calculated according to Carter's method (22). The results of fat mass are expressed in 
kilograms, and the percentage of regional fat mass was calculated to analyze the differences between central (trunk) and peripheral (extremity) distribution of fat tissue. The percentage of trunk fat (PTF), percentage of extremity fat (PEF), and ratio of trunk fat to extremity fat (RTEF) were calculated using the following formulas: PTF, total trunk fat/total fat $\times 100$; PEF, (upper + lower extremities fat/total fat) $\times 100$; and RTEF, PTF/PEF. In addition, total lean mass $(\mathrm{kg})$ was measured in the same anatomical locations as fat and the percentage of body fat were also calculated. Percentage of extremity lean mass was also calculated. In the control group, these variables were also analyzed and calculated.

\section{Statistical analysis}

Results are expressed as mean \pm s.D. The normal distribution of each parameter in all groups was assessed, and differences between controls and BDs were analyzed by paired Student's $t$-test if a normal distribution was previously obtained, or by Wilcoxon paired sample test if not. Comparison of baseline measurements and changes over time in BDs were made by ANOVA with repeated measures, followed by Bonferroni's post hoc test. Pearson's correlation coefficient was used to investigate the association between the parameters studied. The level of significance chosen was $P<0.05$. Data were analyzed using SPSS (15.0) for Windows (MapInfo Corporation, Troy, NY, USA).

\section{Results}

\section{Clinical data and puberty}

Anthropometric parameters and BA are shown in Table 1. During the follow-up period, BMI showed a recovery $(P<0.05)$ at 36 months in BDs. GV was normal, and BA was delayed during the study $(-0.5 \pm 0.8$ years). Total height gain was $7 \pm 3 \mathrm{~cm}$ (range: 1.7-23.7 cm). The interval between the onset of puberty in this group and the age at which menarche occurred was $2.5 \pm 1.0$ years (range: 1.6-4.4). The mean age for menarche was $13.3 \pm 0.4$ years of chronological age (range: 12.1-16.6 years) and
$13.0 \pm 1.0$ years of BA. In the control group, the mean age for menarche was $12 \pm 0.1$ years of chronological age and $12.0 \pm 0.5$ years of BA. At 36 months, $70 \%$ of the BDs had reached menarche. There was a progressive improvement in the height prognosis during monitoring, and at 36 months it was $0.6 \pm 0.7$ SDS with respect to the target height. Caloric intake was found to be insufficient for physical exercise performed in BDs, according to the guidelines of the Food and Nutrition Board of the Institute of Medicine of the National Academy, Washington, DC, USA (20).

\section{Biochemical data}

At baseline, leptin levels (Fig. 1A) and the ratio of leptin/soluble leptin receptor (L/sObr ratio; Fig. 1C) were significantly lower in BDs than in controls, and leptin receptor (sObr) levels (Fig. 1B) were significantly higher in BDs than in controls. During follow-up there was an increase in leptin and the L/sObr ratio (Fig. 1C) and a decrease in sObr (Fig. 1B).

At Tanner stage II, there was a positive correlation between leptin levels and total body fat $(r=0.777$, $P<0.05 ; r=0.594, P<0.01)$ and BMI $(r=0.521$, $P<0.05 ; r=0.62, P<0.05$ in the control group and BDs respectively). There was also a correlation between the $\mathrm{L} / \mathrm{sObr}$ ratio and total fat $(r=0.501$, $P<0.05)$ and trunk fat $(r=0.58, P<0.01)$ in the BDs and with lower extremity fat $(r=0.821, P<0.01$; $r=0.475, P<0.05$ in both the control group and BDs respectively). In BD at Tanner III, leptin levels positively correlated with total body fat $(r=0.521, P<0.05)$ and lower extremity fat $(r=0.547, P<0.05)$, and in BD at Tanner V, leptin levels positively correlated with lower extremity fat $(r=0.879, P<0.05)$. We did not find a relationship between leptin or $\mathrm{L} / \mathrm{sObr}$ ratio with age of menarche.

Adiponectin levels were elevated in BDs during the different stages of puberty compared to controls $(P<0.01)$, and there was an increase at Tanner $\mathrm{V}$ with respect to baseline levels $(P<0.01$; Fig. 1D). There was a positive correlation between adiponectin and lean mass at Tanner II in both controls $(r=0.817$, $P<0.007)$ and BDs $(r=0.481, P<0.02)$. Furthermore, we found a positive correlation between adiponectin

Table 1 Anthropometric parameters and bone age in ballet dancers.

\begin{tabular}{|c|c|c|c|c|c|c|c|c|c|}
\hline & CA (yr) & BMI (SDS) & $\mathbf{H}$ (SDS) & $\begin{array}{l}\text { TH-H } \\
\text { (SDS) }\end{array}$ & $\mathbf{G V}(\mathrm{cm} / \mathrm{yr})$ & $\begin{array}{l}\text { GV (SDS } \\
\text { for CA) }\end{array}$ & BA & BA-CA & $\begin{array}{l}\text { Energy intake } \\
\text { (kcal/day) }\end{array}$ \\
\hline Basal & $11.3 \pm 0.8$ & $-0.8 \pm 0.5$ & $-0.3 \pm 0.8$ & $-0.1 \pm 0.9$ & & & $10.6 \pm 0.5$ & $-0.7 \pm 0.7$ & $2192 \pm 414$ \\
\hline 12 months & $12.2 \pm 0.8$ & $-0.4 \pm 0.8$ & $-0.4 \pm 1.1$ & $-0.4 \pm 0.8$ & $6.8 \pm 0.4$ & $0.9 \pm 1.6$ & $11.5 \pm 0.5$ & $-0.6 \pm 0.8$ & $2107 \pm 377$ \\
\hline 24 months & $13.0 \pm 0.8$ & $-0.5 \pm 0.5$ & $-0.09 \pm 0.9$ & $-0.6 \pm 0.7^{*}$ & $6.8 \pm 0.3$ & $1.2 \pm 1$ & $12.4 \pm 0.6$ & $-0.5 \pm 0.8$ & $2077 \pm 371$ \\
\hline 36 months & $14.1 \pm 0.8$ & $-0.3 \pm 0.6^{*}$ & $0.03 \pm 1.1^{*}$ & $-0.6 \pm 0.6^{*}$ & $3.6 \pm 0.6$ & $1.1 \pm 1.9$ & $13.6 \pm 0.6$ & $-0.5 \pm 1.0$ & $1834 \pm 235$ \\
\hline
\end{tabular}

${ }^{\star} P<0.05$ intra-group at different moments with baseline. yr, year; cm, centimeter; CA, chronological age; BA, bone age; BMI, body mass index; GV, growth velocity; $\mathrm{H}$, height; $\mathrm{W}$, weight; $\mathrm{TH}$, target height. 
A
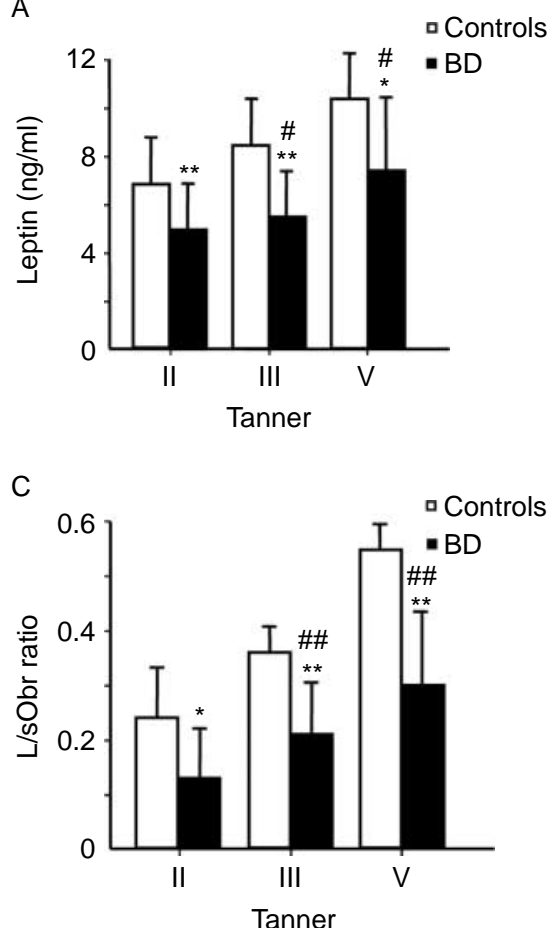
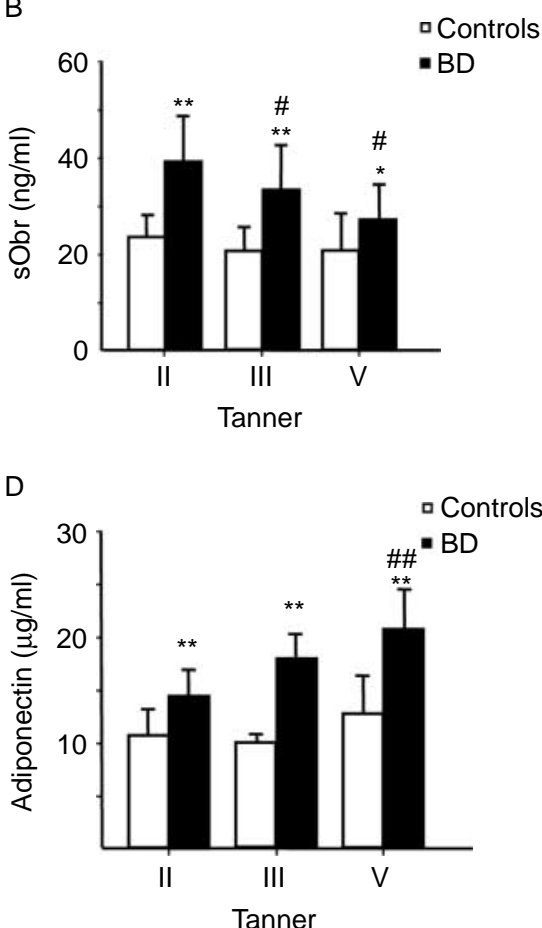

Figure 1 Leptin (A), sObr (B), L/sObr ratio $(C)$, and adiponectin (D) in ballet dancers throughout puberty. ${ }^{\#} P<0.05$ compared within same group at different moments with baseline; ${ }^{\star} P<0.05$ compared with the control group; ${ }^{\#} P<0.05,{ }^{\# \#} P<0.01 ;{ }^{*} P<0.05$, ${ }^{\star *} P<0.01$. levels and BMD in both controls and BDs at Tanner II ( $r=0.775, P<0.05 ; r=0.839, P<0.01$ respectively $)$ and at Tanner III $(r=0.438, P<0.04)$ in the BD group, as well as a negative correlation between adiponectin levels and total fat mass $(r=-0.430, P<0.05)$ at Tanner II.

\section{Body composition}

Body fat mass and regional fat distributions are shown in Table 2. Total fat and trunk and extremity fat mass were decreased in BDs throughout the study period. The PTF was decreased at all time points $(P<0.01)$, with a normal PEF. The RTEF was also diminished throughout the study $(P<0.01)$.

Total lean mass and lean mass of the lower extremities (LEs) were elevated with respect to the control group at Tanner II, but total lean mass returned to normal values at Tanner III with a persistent increase of lean mass in LE (Table 2).

Total body BMD and the BMD in all locations that were analyzed (LSv from L1 to L4, FN, femoral trochanter, intertrochanter region, and WT) were normal when compared to the control group (data not shown).

Table 2 Total and regional fat mass and lean mass distribution in ballet dancers.

\begin{tabular}{|c|c|c|c|c|c|c|}
\hline & \multicolumn{2}{|c|}{ Tanner II } & \multicolumn{2}{|c|}{ Tanner III } & \multicolumn{2}{|c|}{ Tanner V } \\
\hline & Control & $\mathrm{BD}$ & Control & $\mathrm{BD}$ & Control & $\mathrm{BD}$ \\
\hline Fat mass $(\mathrm{kg})$ & $10.2 \pm 4.3$ & $4.9 \pm 2.6^{\ddagger}$ & $14.6 \pm 3.7$ & $7.4 \pm 12.2^{\dagger}$ & $15.1 \pm 3.5$ & $10.5 \pm 3.9^{\ddagger}$ \\
\hline Trunk fat (kg) & $2.3 \pm 0.9$ & $1.6 \pm 0.7^{\ddagger}$ & $4.4 \pm 3.2$ & $2.6 \pm 1.0^{\dagger}$ & $6.0 \pm 1.3$ & $3.7 \pm 1.6^{\ddagger}$ \\
\hline UEF $(\mathrm{kg})$ & $1.4 \pm 0.9$ & $0.6 \pm 0.4^{\ddagger}$ & $1.3 \pm 0.3$ & $0.9 \pm 0.4^{\ddagger}$ & $1.8 \pm 0.5$ & $1.2 \pm 0.6^{\dagger}$ \\
\hline LEF (kg) & $4.7 \pm 2.1$ & $2.3 \pm 1.0^{\ddagger}$ & $4.9 \pm 1.1$ & $3.7 \pm 1.3^{\dagger}$ & $6.7 \pm 1.8$ & $4.3 \pm 1.6^{\ddagger}$ \\
\hline PTF (\%) & $36.1 \pm 5.3$ & $30.1 \pm 5.8^{\ddagger}$ & $38.4 \pm 3.7$ & $32.1 \pm 2.7^{\dagger}$ & $39.7 \pm 3.6$ & $35.1 \pm 3.9^{\ddagger}$ \\
\hline PEF (\%) & $59.5 \pm 3.5$ & $62.6 \pm 16.4$ & $58.3 \pm 5.3$ & $57.6 \pm 3.3$ & $56.9 \pm 3.4$ & $56.9 \pm 3.4$ \\
\hline RTEF & $0.58 \pm 0.08$ & $0.50 \pm 0.10^{\ddagger}$ & $0.61 \pm 0.06$ & $0.54 \pm 0.06^{\dagger}$ & $0.72 \pm 0.11$ & $0.62 \pm 0.10^{\dagger}$ \\
\hline Lean mass $(\mathrm{kg})$ & $23.9 \pm 2.9$ & $27.1 \pm 4.5^{\dagger}$ & $30.1 \pm 3.5$ & $30.4 \pm 3.3$ & $37.0 \pm 4.0$ & $34.2 \pm 3.5$ \\
\hline UEL (kg) & $2.1+0.2$ & $2.5+0.5^{\dagger}$ & $2.8+0.5$ & $2.7+0.3$ & $3.0+0.3$ & $2.9+0.3$ \\
\hline LEL (kg) & $8.3 \pm 1.0$ & $10.1 \pm 1.7^{\ddagger}$ & $9.4 \pm 1.1$ & $10.9 \pm 1.5^{\ddagger}$ & $11.8 \pm 0.7$ & $13.0 \pm 1.1^{\ddagger}$ \\
\hline PEL (\%) & $43.9 \pm 1.0$ & $46.9 \pm 3.7^{\ddagger}$ & $43.2 \pm 1.4$ & $45.1 \pm 2.0^{\dagger}$ & $43.0 \pm 2.8$ & $46.2 \pm 2.3^{\dagger}$ \\
\hline
\end{tabular}

${ }^{\star} P<0.05$ compared within the same group at different moments with baseline; ${ }^{\dagger} P<0.05$ compared with control group; ${ }^{\ddagger} P<0.01$ compared with control group; UEF, upper extremity fat; LEF, lower extremity fat; PTF, percentage of trunk fat; PEF, percentage of extremity fat; RTEF, ratio of trunk fat to extremity fat; $L$, lean; UEL, upper extremity lean; LEL, lower extremity lean; PEL, percentage of extremity lean. 


\section{Discussion}

Our results demonstrate that BDs exhibit a specific pattern of growth and pubertal development, and that despite the observed delay in skeletal maturation and pubertal progress at the onset of the study, the final height was not affected. We found that BDs had a deficient energy intake for the physical exercise performed, a delay in bone maturation that decreased during pubertal evolution, and a normal GV. There was also a delay of 1 year in the age at menarche. As bone maturation progresses slowly over a long period of time, adequate compensatory catch-up growth may explain the recovery of growth potential as puberty progressed.

Georgopoulos et al. (23) demonstrated that rhythmic gymnasts compensate for their loss of the pubertal growth spurt by late acceleration of linear growth. Furthermore, despite this delay in skeletal maturation, the genetic predisposition for growth is not only preserved, but may even be exceeded (24). Courteix et al. (25) showed that elite rhythmic gymnasts have a decrease in body fat and low energy balance, and this could delay puberty. Indeed, elite rhythmic gymnasts and BDs exhibit a pattern of growth characterized by a delay in skeletal maturation and pubertal development $(1,26)$, as we found here.

The BD group presented alterations in body fat, both in content and distribution. BDs lose less fat in the trunk, with this being similar to what we previously reported in patients with anorexia nervosa (AN) and moderate prolonged malnutrition (21). The RTEF is used to evaluate body fat distribution, and it has been reported that adolescents with $\mathrm{AN}$ and a BMI below -2 SDS with chronic malnutrition have low RTEF, due to a greater reduction in trunk fat mass (21). These findings of body fat distribution are similar to those reported here. Thus, BDs have a normal BMI, but a prolonged decrease in body fat. This observation supports the hypothesis that the duration of decreased body fat is the main determinant in the changes of fat distribution. The preservation of trunk fat in BDs may be related with the pattern of distribution, similar to female anorectic girls. It has been postulated that in adult anorectic females, the marked hypercortisolemia could influence central fat distribution (27). In addition, altered GH secretion dynamics in these patients (28) could be involved in fat distribution; unfortunately, we did not perform studies of GH secretion and cortisol levels in BDs.

BMD in BDs is normal throughout the study period. In fact, moderate physical activity favors bone mineralization and reduces the rate of bone loss (6). Daly et al. (29) showed that during training, rhythmic gymnasts experience frequent high-impact stress on the upper and lower extremities. Although the delay in sexual development may adversely affect bone quality and functional strength, exercise has benefits similar to weight-bearing on bone mass accretion during adolescence and young adulthood.
Insufficient caloric intake for the level of physical activity has been proposed as a factor in the genesis of exercise-associated reproductive dysfunction and osteopenia, and this may be an adaptive response to chronic low energy intake (30). The exercise performed by BDs could alter leptin release and may lead to a reduction in GnRH, LH, and FSH secretion, and subsequently, reduced ovarian estrogens (31). We found that the total fat mass content and fat content in all locations that were analyzed were lower in BDs when compared to controls. This is probably caused by intensive exercise and undernutrition, and this could help to explain why BDs have a delay in both bone maturation and the age at menarche.

A critical minimum amount of body fat is necessary for resumption of menses in malnourished states and for the beginning of puberty (32). Indeed, the increase in leptin levels after fat mass recovery is one of the determinants of menses resumption (33). These findings support the hypothesis that a critical fat mass is necessary for the recuperation of menstrual function, and that leptin plays a relevant role in gonadal function (34). Different studies performed in elite female athletes show that reduced leptin levels may be related to an insufficient nutritional intake, although this decrease could also be influenced by physical activity (35). Kaufman et al. hypothesized that the correlation between low resting metabolic rate, leptin levels and bone density may be related to nutritional habits in BDs (34). Similarly, we showed that leptin could be implicated in the pubertal delay in rhythmic gymnasts (3).

Serum leptin receptor levels in BDs are increased, and this may represent a protective mechanism that decreases free leptin bioavailability, which could represent further energy conservation (36). In lean males, including those physically active, leptin receptor concentrations are increased, which results in low free leptin concentrations. Thus, sObR levels may be an indirect index of free leptin levels and useful in the comparison of physically active and lean people (36). According to the leptin receptor and leptin levels found in this and other studies, lean people with higher sObR and lower leptin levels do not display the leptin resistance phenomenon that occurs in obese subjects (37).

Serum adiponectin concentrations are high in constitutionally thin individuals and low in obese people (38). We found that adiponectin levels were increased in BDs, with a further increase during puberty. Okamoto et al. (39) demonstrated that adiponectin levels are negatively associated with BMI and fat content. The mechanisms implicated in the regulation of adiponectin remain unknown, but exercise increases adiponectin levels $(16,40)$, as shown here. Furthermore, we found that lean mass is higher in BDs, and that there is a positive correlation between adiponectin levels and lean mass. This could also be a direct result of exercise, as it 
increases the expression of adiponectin and its receptors in muscle (13). Moreover, the change in lean mass distribution with an increase in the lower extremities may be due to the type of intensive training.

Adiponectin is negatively correlated with body weight and central adiposity, and its receptors are present in human bone-forming cells, suggesting that adiponectin may link bone and fat metabolism (14). Richards et al. (41) found that in nondiabetic women, the increase in adiponectin is associated with a decrease in BMD. In contrast, we found a positive relationship between adiponectin and BMD, with high serum adiponectin levels and normal BMD, possibly due to the intense exercise. Exercise increases adiponectin levels, and this may maintain a normal BMD in BDs. It has been reported that adiponectin promotes osteogenesis, increasing osteogenic markers and augmenting osteoblast differentiation (42).

One caveat that should be taken into consideration when evaluating these results is that the control subjects were from a cross-sectional population, while the BDs were followed prospectively. Although it could be of interest to follow the parallel evolution of both groups, the control population used in this study may present some advantages, especially regarding comparable anthropometric characteristics at a given age. In addition, in this study design, we were able to maintain the number of control subjects at each time point.

Here, we demonstrate that a negative energy balance together with maintained physical exercise induced modifications in body composition in BDs. Changes in leptin and adiponectin levels appear to be more related to total fat content than to BMI. Finally, the onset and delayed progress of puberty may be related to an inadequate energy balance due to intense physical exercise.

\section{Declaration of interest}

The authors declare that there is no conflict of interest that could be perceived as prejudicing the impartiality of the research reported.

\section{Funding}

This work was supported by CIBEROBN (CB 06/03/0022) Instituto de Salud Carlos III and the Fundación Endocrinología y Nutrición.

\section{References}

1 Castelo-Branco C, Reina F, Montivero AD, Colodrón M \& Vanrell JA. Influence of high-intensity training and of dietetic and anthropometric factors on menstrual cycle disorders in ballet dancers. Gynecological Endocrinology 200622 31-35.

2 Warren MP. The effects of exercise on pubertal progression and reproductive function in girls. Journal of Clinical Endocrinology and Metabolism 198051 1150-1157.
3 Muñoz MT, De la Piedra C, Barrios V, Garrido G \& Argente J. Changes in bone density and bone markers in rhythmic gymnasts and ballet dancers: implications for puberty and leptin levels. European Journal of Endocrinology 2004151 491-496.

4 Muñoz MT, Garrido G, Soriano L, Martínez J, Donoso MA \& Hernández M. Aspectos nutricionales en adolescentes deportistas. Revista Española de Pediatría 200259 222-231.

5 D’Alessandro C, Morelli E, Evangelisti I, Galetta F, Franzoni F, Lazzeri D, Piazza M \& Cupisti A. Profiling the diet and body composition of subelite adolescent rhythmic gymnasts. Pediatric Exercise Science 200719 215-227.

6 Nilsson M, Ohlsson C, Mellström D \& Lorentzon M. Previous sport activity during childhood and adolescence is associated with increased cortical bone size in young adult men. Journal of Bone and Mineral Research 200924 125-133.

7 Lima F, De Falco V, Baima J, Carazzato JG \& Pereira RM. Effect of impact load and active load on bone metabolism and body composition of adolescent athletes. Medicine and Science in Sports and Exercise 200133 1318-1323.

8 Henderson NK, White CP \& Eisman JA. The roles of exercise and fall risk reduction in the prevention of osteoporosis. Endocrinology and Metabolism Clinics of North America 199827 369-387.

9 Quennell JH, Mulligan AC, Tups A, Liu X, Phipps SJ, Kemp CJ, Herbison AE, Grattan DR \& Anderson GM. Leptin indirectly regulates $\mathrm{GnRH}$ neuronal function. Endocrinology 2009150 2805-2812.

10 Argente J, Barrios V, Chowen JA, Sinha MK \& Considine RV. Leptin plasma levels in healthy Spanish children and adolescents, children with obesity, and adolescents with anorexia nervosa and bulimia nervosa. Journal of Pediatrics 1997131 833-838.

11 Friedman JM \& Halaas JL. Leptin and the regulation of body weight in mammals. Nature $1998395763-770$.

12 Yang G, Ge H, Boucher A, Yu X \& Li C. Modulation of direct leptin signaling by soluble leptin receptor. Molecular Endocrinology 2004 18 1354-1362.

13 Kriketos AD, Gan SK, Poynten AM, Furler SM, Chisholm DJ \& Campbell LV. Exercise increases adiponectin levels and insulin sensitivity in humans. Diabetes Care 200427 629-630.

14 Blüher M, Williams CJ, Klöting N, Hsi A, Ruschke K, Oberbach A, Fasshauer M, Berndt J, Schön MR, Wolk A, Stumvoll M \& Mantzoros CS. Gene expression of adiponectin receptors in human visceral and subcutaneous adipose tissue is related to insulin resistance and metabolic parameters and is altered in response to physical training. Diabetes Care 200730 3110-3115.

15 Martos-Moreno GA, Barrios V \& Argente J. Normative data for adiponectin, resistin, interleukin 6 , and leptin/receptor ratio in a healthy Spanish pediatric population: relationship with sex steroids. European Journal of Endocrinology 2006155 429-434.

16 Shibata R, Ouchi N \& Murohara T. Adiponectin and cardiovascular disease. Circulation Journal 200973 608-614.

$17 \mathrm{Vu} \mathrm{V}$, Riddell MC \& Sweeney G. Circulating adiponectin and adiponectin receptor expression in skeletal muscle: effects of exercise. Diabetes/Metabolism Research and Reviews 200723 600-611.

18 Hernández M, Castellet J, Narvaíza JL, Rincón JM, Ruíz I, Sánchez E, Sobradillo B \& Zurimendi A. Curvas y Tablas de Crecimiento, Instituto de Investigación sobre Crecimiento y Desarrollo. Fundación Faustino Orbegozo Madrid: Editorial Garsi, 1988.

19 Greulich WW \& Pyle SI. Radiographic Atlas of Skeletal Development of Hand and Wrist. edn 2 Stanford, CA, USA: Stanford University Press, 1959.

20 Food and Nutrition Board, I.O.M. Dietary Reference Intakes for Energy, Carbohydrate, Fiber, Fat, Fatty Acids, Cholesterol, Protein and Amino Acids, Washington, DC, USA: National Academy Press, 2006.

21 García De Álvaro MT, Muñoz MT, Barrios V, Martínez G, Martos-Moreno GA, Hawkins F \& Argente J. Regional fat distribution in adolescents with anorexia nervosa: effect of duration of malnutrition and weight recovery. European Journal of Endocrinology 2007157 473-479. 
22 Carter DR, Bouxsein ML \& Marcus R. New approaches for interpreting projected bone densitometry data. Journal of Bone and Mineral Research 19927 137-145.

23 Georgopoulos NA, Markou KB, Theododopoulou A, Vagenakis GA, Bernadot D, Leguise M, Dimopoulos JCA \& Vagenakis AG. Height velocity and skeletal maturation in elite female rhythmic gymnasts. Journal of Clinical Endocrinology and Metabolism 2001 86 5159-5164.

24 Bass S, Bradney M, Pearce G, Hendrich E, Inge K, Stuckey S, Lo SK \& Seeman E. Short stature and delayed puberty in gymnasts: influence of selection bias on leg length and the duration of training on trunk length. Journal of Pediatrics 2000136 149-155.

25 Courteix D, Lespessailles E, Obert P \& Benhamou CL. Skull bone mass deficit in prepubertal highly-trained gymnast girls. International Journal of Sports Medicine 199920 328-333.

26 Warren MP, Brooks-Gunn J, Fox RP, Holderness CC, Hyle EP \& Hamilton WG. Osteopenia in exercise-associated amenorrhea using ballet dancers as a model: a longitudinal study. Journal of Clinical Endocrinology and Metabolism $2002873162-3168$.

27 Epel ES, McEwen B, Seeman T, Matthews K, Castellazzo G, Brownell KD, Bell J \& Ickovics JR. Stress and body shape: stressinduced cortisol secretion is consistently greater among women with central fat. Psychosomatic Medicine $200062623-632$.

28 Argente J, Caballo N, Barrios V, Muñoz MT, Pozo J, Chowen JA, Morandé G \& Hernández M. Multiple endocrine abnormalities of the growth hormone and insulin-like growth factor axis in patients with anorexia nervosa: effect of short- and long-term weight recuperation. Journal of Clinical Endocrinology and Metabolism 199782 2084-2092.

29 Daly RM, Rich PA \& Klein R. Influence of high impact loading on ultrasound bone measurements in children: a cross-sectional report. Calcified Tissue International 199760 401-404.

30 Quintas ME, Ortega RM, López-Sobaler AM, Garrido G \& Requejo AM. Influence of dietetic and anthropometric factors and of the type of sport practised on bone density in different groups of women. European Journal of Clinical Nutrition $2003 \mathbf{5 7}$ S58-S62.

31 Mitchell M, Armstrong DT, Robker RL \& Norman RJ. Adipokines: implications for female fertility and obesity. Reproduction 2005 130 583-597.
32 Frisch RE \& McArthur JW. Menstrual cycles: fatness as a determinant of minimum weight for height necessary for their maintenance or onset. Science $1974 \mathbf{4 1 5} 949-951$.

33 Chehab FF, Qiu J, Mounzih K, Ewart-Toland A \& Ogus S. Leptin and reproduction. Nutrition Reviews 200260 S39-S46.

34 Kaufman BA, Warren MP, Domínguez JE, Wang J, Heymsfield SB \& Pierson RN. Bone density and amenorrhea in ballet dancers are related to a decreased resting metabolic rate and lower leptin levels. Journal of Clinical Endocrinology and Metabolism 200287 2777-2783.

35 Khosla S. Editorial: leptin: central or peripheral to the regulation of bone metabolism? Endocrinology $2002434161-4164$.

36 Tsao TH, Yang JB, Yang CB, Hsu CH \& Liou TL. The soluble leptin receptor of regular exercisers. International Journal of Sports Medicine $2007 \mathbf{2 8} 732-735$.

37 El-Haschimi K, Pierroz DD, Hileman SM, Bjørbaek C \& Flier JS. Two defects contribute to hypothalamic leptin resistance in mice with diet-induced obesity. Journal of Clinical Investigation $2000 \mathbf{1 0 5}$ 1827-1832.

38 Asayama K, Hayashibe H, Dobashi K, Uchida N, Nakane T, Kodera K, Shirahata A \& Taniyama M. Decrease in serum adiponectin level due to obesity and visceral fat accumulation in children. Obesity Research 200311 1072-1079.

39 Okamoto Y, Kihara S, Funahashi T, Matsuzawa Y \& Libby P. Adiponectin: a key adipocytokine in metabolic syndrome. Clinical Science $2006110267-278$.

40 Simpson KA \& Singh MA. Effects of exercise on adiponectin: a systematic review. Obesity 200816 241-256.

41 Richards JB, Valdes AM, Burling K, Perks UC \& Spector TD. Serum adiponectin and bone mineral density in women. Journal of Clinical Endocrinology and Metabolism 200792 1517-1523.

42 Lee HW, Kim SY, Kim AY, Lee EJ, Choi JY \& Kim JB. Adiponectin stimulates osteoblast differentiation through induction of COX2 in mesenchymal progenitor cells. Stem Cells 200927 2254-2262.

Received 14 January 2010

Accepted 9 February 2010 